\title{
Direito, literatura e prática judicial na Goa de outrora - o caso dos advogados provisionários ( $2^{a}$ parte)
}

Luís Pedroso de lima Cabral de Oliveira Instituto Superior de Gestão e Tecnologia (Leiria, Portugal)

\begin{abstract}
RESUMO: O PRESENTE TRABALHO - QUE SE ANCORA EM DOIS TEXTOS ESCRITOS PELOS AUTORES GOESES JOSÉ DA SILVA COELHO E ALBERTO DE MENESES RODRIGUES - TEM POR PROPÓSITO INQUIRIR DE QUE FORMA O RECURSO ÀS TÉCNICAS QUE VÊM SENDO DESENVOLVIDAS NO ÂMBITO DO LAW AND LITERATURE MOVEMENT PODE REVELAR-SE ÚTIL PARA O ESTUDO DE MATÉRIAS DA ÁREA HISTÓRICOJURÍDICA. ESSE GÊNERO DE ANÁLISE PERMITE UMA COMPREENSÃO MAIS ALARGADA DAS REALIDADES SOCIAL E JURÍDICA (E SUAS INTERAÇÕES) EM GOA ENTRE 1880 E 1960, NOMEADAMENTE NO QUE DIZ RESPEITO AOS CHAMADOS ADVOGADOS PROVISIONÁRIOS.
\end{abstract}

ABSTRACT: THE PRESENT PAPER AIMS TO ILLUSTRATE THE USEFULNESS OF TECHNIQUES DEVELOPED BY THE LAW AND LITERATURE MOVEMENT TO HISTORICAL-JURIDICAL STUDIES. THIS SORT OF ANALYSIS ENABLES US TO ACQUIRE DEEPER KNOWLEDGE OF THE SOCIAL AND LEGAL REALITIES (AND THEIR INTERACTIONS) IN GOA DURING THE LATE PORTUGUESE PERIOD (1880-1960). HERE I AIM TO SHOW HOW TWO LITERARY TEXTS WRITTEN BY GOAN AUTHORS (JOSÉ DA SILVA COELHO AND ALBERTO DE MENESES RODRIGUES) CAN BE USED TO OBTAIN A MORE REALISTIC VISION OF THE GOAN LAWYERS USUALLY CALLED ADVOGADOS PROVISIONÁRIOS.

PALAVRAS-CHAVE: GOA, DIREITO, LITERATURA, ADVOGADOS PROVISIONÁRIOS. KEYWORDS: GOA, LAW, LITERATURE, ADVOGADOS PROVISIONÁRIOS. 


\section{Sob o ângulo de Alberto de Menezes Rodrigues}

or outro lado, como acima explicamos, selecionamos um trabalho em que, contrariamente aos textos citados de Silva Coelho, se procura passar uma ideia positiva de um profissional do foro goês - desta feita, de Marcelo de Almeida, advogado provisionário em Mormugão, personagem central do conto "A rapariga do roseiral", que com vários outros integra a coletânea Flor campestre, da autoria de Alberto de Meneses Rodrigues (1968, p. 211 e segs.). Sendo embora já um trabalho da segunda metade do século XX (mais concretamente, de 1968), nele perpassam ainda - desde logo por se reportar a um período ainda anterior a 1961 - inúmeras referências que demonstram que, no que ao exercício do direito por esses advogados provisionários diz respeito, muito pouco tinha cambiado em cem anos. $\mathrm{O}$ contraponto que pretendemos operar com o texto acima analisado de Silva Coelho tem, cremos, cabimento, se recordarmos o que nos diz sobre o escritor Vimala Devi e Manuel de Seabra:

Alberto de Meneses Rodrigues (1904) é autor de dois livros de contos e novelas: Caminhos de Luze Flor Campestre, e constitui um caso muito especial na literatura indo-portuguesa. Ao contrário de José da Silva Coelho, este escritor está perfeitamente integrado e identifica-se intimamente com a dialética da sociedade em que vive. $\mathrm{O}$ antagonismo escritor-público, ou o inconformismo do escritor perante a sociedade, que é condição frequente da tomada de consciência tanto para o escritor como para a sociedade, está ausente dos seus contos e novelas. Por outro lado, a acentuar ainda mais o carácter insólito da sua posição, tratase de um escritor simultaneamente idealista e realista. (...) curiosamente, este escritor consegue por vezes superar esta circunstância e ser, ao mesmo tempo, um escritor realista (DEVI e SEABRA, 1971, vol. I, p. 222).

As particularidades do autor, nomeadamente a franqueza, por vezes desconcertante, com que descreve as situações e personagens, são da maior utilidade para os que querem conhecer melhor a sociedade goesa da época. Devi e Seabra não deixam, naturalmente, de o referir:

A sua honestidade [do autor] não permite que o real deforme o ideal e é rigidamente fiel ao mundo que cria. E essa honestidade torna os seus livros do- 
cumentos de grande valor sociológico, pois, embora se trate indubitavelmente de ficção, são autênticos e exatos até aos mais ínfimos pormenores. Alberto de Meneses Rodrigues parece não ter consciência do ridículo, do vulgar, do enfatuado das várias personagens e situações que cria. A sua atitude perante todas elas é a mesma: a sua reprodução fiel e, por isso, talvez por vezes desconcertante. Trata-se de um escritor que leva todas as suas personagens a sério. O seu grande prejuízo é que estas são quase sem exceção extraídas às classes médias, com todas as ilusões que historicamente a caracterizam, e são, por isso, com demasiada frequência, ridículas, e o autor ama-as tais como são (RODRIGUES, 1968, p. 223).

A que conduz tanta honestidade, mesmo na crença do autor de que suas personagens são, sobretudo, dignas, boas e ilustradas (como é o caso do advogado Marcelo de Almeida)? A descrição crua das suas vidas e ações acaba por levar o leitor a considerar o caricato e a pretensão de muitas das cenas e comportamentos descritos. $\mathrm{Na}$ verdade - e no que, no conto em análise, aos advogados provisionários diz respeito - a visão cândida de Meneses Rodrigues acaba por ser, inesperadamente, tão demolidora como a (intencional) crítica cáustica de Silva Coelho.

Debrucemo-nos, então, sobre "A rapariga do roseiral", tendo em vista as coordenadas acima referidas: reflexos, no conto, de (1) formação jurídica; (2) prática forense; e (3) relacionamento e procedimentos do advogado para com os demais (colegas, magistrados ou "leigos").

O esquema básico do conto é assaz simples. Um jovem causídico, recémhabilitado, fixa-se na comarca de Mormugão, onde se instala em casa de D. Antonieta Dourado e Veloso, que arrendava quartos a hóspedes. Cedo tem um companheiro de aposento, Pelágio de Magalhães, com quem estreita relações de amizade e a quem muito auxilia a casar-se com Silvana, uma jovem de condição social muito inferior (uma "rapariga do povo" que, no entanto, como sublinha o autor, era mais escolarizada e refinada do que a maioria das demais). Marcelo acaba também por se apaixonar, mas por uma rapariga da elite chardó local - e, naturalmente, culta (mais culta, apesar de tudo, do que a esforçada Silvana, pois "tinha concluído o Curso Complementar de Letras" (RODRIGUES, 1968, p. 223) e pertencente a uma família... de advogados. Depois de inúmeras peripécias, que envolvem uma tentativa de suicídio de 
Pelágio face aos inultrapassáveis prejuízos castistas do seu pai (pois eles eram "brâmanes de primeira classe") tudo acaba bem: os dois amigos casados com as respectivas apaixonadas e Rútila - irmã de Pelágio, que entra em cena já a meio do conto - com um jovem médico de Margão, rico proprietário, licenciado em Portugal, lente da Escola Médico-Cirúrgica de Goa e (segundo se depreende do texto) brâmane (trata-se, portanto, de um verdadeiro protótipo do casamento ideal para as elites naturais de então).

(1) No que diz respeito à formação jurídica, o conto de Meneses Rodrigues é menos detalhado do que o texto de Silva Coelho - provavelmente por aquele não considerar que a formação usual dos causídicos goeses fosse merecedora de críticas tão acesas. Assim, indica-se somente que:

Fizera os meus exames no Tribunal da Comarca das Ilhas, e, tendo-me sido concedida pelo Presidente da Relação provisão para advogar na comarca de Salsete, dez dias depois eu estava em Vasco da Gama [junto a Mormugão] para exercer a profissão que escolhera (RODRIGUES, 1968, p. 223).

O autor informa-nos, ainda, que Marcelo concluíra a sua formação jurídica com grande sucesso, graças a um diálogo que o mesmo trava com a sua futura sogra, durante um jantar de baile no (seleto, para a época e lugar) Grêmio Literário e Recreativo, ao qual Marcelo comparecera, nas suas próprias palavras, "com o meu smoking impecável":

- Meu marido tece grandes elogios ao doutor. Diz que é um advogado espertíssimo. Aquela sua defesa foi brilhantíssima. Onde passou os seus exames de advogado?

- No Tribunal da Comarca das Ilhas.

- Teve certamente notas altas.

- Todos os três do júri me deram a nota máxima. (RODRIGUES, 1968, p. 232)

(2) É no que toca à prática forense que, a nosso ver, o texto assume maior interesse. Isso desde logo por descrever, com grande minúcia, um dos primeiros julgamentos em que Marcelo de Almeida tomava parte, e que - pela prestação que aí teve (!) - lhe granjeou notoriedade. Apesar de longo, cremos que o texto merece ser reproduzido, não só pela pormenorizada exposição 
de uma sessão de um tribunal goês, como também pela descrição do papel do advogado.

Uma manhã veio procurar-me um sujeito para me pedir que fosse seu advogado no Tribunal, pois que alguém se tinha queixado de que fora por ele espancado. Declarou-me o homem que o queixoso o esbofeteara, depois de lhe ter dirigido dois ou três insultos provocantes, e ele, irritado, o empurrara, e com o ímpeto do empurrão o homem se estatelara no chão, após ter batido a cabeça numa palmeira.

Eu acedi ao pedido.

Meses depois, no dia do julgamento, fiz uma defesa brilhante do réu. Clamei, diante do Juiz e do Subdelegado do Procurador da República, que a queixa era um acervo de mentiras. "O réu foi insultado e rijamente esbofeteado, e era, portanto, natural que ele se irritasse. Essa ira o levou a empurrar o queixoso, que caiu no chão, depois de bater a cabeça numa palmeira. Teve, é certo, uma ferida. Essa ferida já sarou, vendo-se agora a cicatriz, cuja pequenez me permite afirmar que aquilo foi uma ferida sem importância, confirmando-se, assim, o que duas testemunhas de defesa disseram no tocante à mesma.

Baseando-me nos depoimentos das quatro testemunhas apresentadas pelo réu, pulverizei o testemunho de dois indivíduos que depuseram, falsamente, que a ferida tinha sido causada por duas bengaladas do réu. Lembrei que duas testemunhas deste haviam declarado que Tolentino Cabral (testemunha do autor) comera com elas baji-puri e tomara chá, no café da aldeia, à hora em que ocorrera o conflito, e concluí ser falso, absolutamente falso, que ele o tivesse presenciado, pois o mesmo se dera no prédio do réu, que fica a grande distância do café - mais de um quilómetro. E baixando um pouco a voz, lancei ao ar uma interrogação, com sorriso nos lábios: - "Teria ele sido dotado pelo Criador com o dom da ubiquidade?” (Risos no auditório). Bradei que outras duas testemunhas haviam afirmado que a testemunha do queixoso, Romão da Fonseca, estava de relações cortadas com o réu por este lhe ter recusado arrendar uma várzea. "Devo dizer que o réu estava no seu legítimo direito de lho recusar, pois, tendo-lhe sido arrendada a várzea em relação ao ano agrícola anterior, Romão da Fonseca só pagou ao proprietário metade da renda estipulada, não obstante a produção ter sido muito boa, e o contrato não ia para além dum ano. O depoimento de Fonseca não passa duma desforra vil, duma vingança baixa, pois o que ele pretende é ver o réu 
envergonhado com uma prisão, mas eu garanto a todos quantos aqui estão que não há-de lograr o que deseja, porque confio na integridade do douto Juiz que preside a esta sessão e estou certo de que a palavra "justiça”, que os dicionários registam, terá aqui, nesta sala, o seu real significado."

Relancei um olhar pelo auditório e reparei que todos me escutavam com grande atenção, e isto me animou muito. Aos meus lábios afloravam metáforas, antíteses, apóstrofes, todas essas figuras de retórica que embelezam o discurso. Eu próprio, depois de cessar de falar e lançar um olhar de triunfo para o advogado do autor, me admirei da minha facúndia.

Três horas depois, o Juiz lia a sentença, que absolvia o réu (RODRIGUES, 1968, p. 211-213).

Reafirme-se, neste passo, o que acima foi referido: apesar do caricato de muitas das situações narradas, em nenhum momento o autor pretende retirar créditos ou méritos ao seu personagem. A "pulverização" das testemunhas, a interrogação sobre o dom da ubiquidade, a menção à palavra justiça "que os dicionários registam”, as "metáforas, antíteses, apóstrofes, todas essas figuras de retórica que embelezam o discurso" que afloravam aos seus lábios - tudo isso era motivo para facúndia. Para todos os efeitos, o julgamento é exposto como se tivesse sido algo de notável, uma (nas palavras de Marcelo de Almeida) "defesa brilhante".

Para além dessa longa narração, são várias as referências à vida profissional de Marcelo. Ou desloca-se ao tribunal "para uma diligência” (RODRIGUES, 1968, p. 218); ou descansa após “escrever uma extensa minuta para um requerimento, a qual tinha de ser entregue às onze horas, a fim de ele a mandar dactilografar em folha selada e dar entrada no Tribunal antes das treze horas do mesmo dia" (RODRIGUES, 1968, p. 219); ou anda "assoberbado" com o seu "trabalho profissional" (RODRIGUES, 1968, p. 220); ou procura recuperar dos esforços físicos gastos na defesa dos seus clientes ("Dois dias depois, pelas seis horas da tarde, encaminhei-me para a praia, a fim de aspirar ar mais oxigenado e fortificar os pulmões, que se sentiam exaustos por eu ter berrado muito no tribunal" (RODRIGUES, 1968, p. 222).

(3) Por fim, no atinente às relações com os demais, há que proceder a uma distinção. Por um lado, é descrita a reação do magistrado local face à intervenção em tribunal de Marcelo de Almeida: 
Quando, passado um quarto de hora, fui ao Juiz para lhe pedir que me fosse passada uma certidão (era um assunto diferente), pois que o escrivão, por causa de uma certa dificuldade, quisera que eu lhe falasse sobre o assunto, o ilustre magistrado levantou-se da cadeira e felicitou-me pela defesa, que considerou muito brilhante (RODRIGUES, 1968, p. 214).

Aos colegas, depois do julgamento, oferece cerveja, sendo brindado com um discurso, no qual se dá a entender que o seu desempenho lhe garantiria fama e sucesso na profissão escolhida - e, mais uma vez o salientamos, nada é descrito em tons irônicos:

Os meus colegas levaram-me para um bar, onde lhes ofereci cerveja. Ainda me lembro [trata-se de um conto assente nas suas memórias, coligidas muitos anos depois da ocorrência dos vários acontecimentos descritos] do pequeno discurso que proferiu um deles, discurso em que me chamou orador de raça e augurou que eu viria a ser um dos mais brilhantes valores do foro goês (RODRIGUES, 1968, p. 214).

Quanto à restante população - ou seja, aos leigos em termos jurídicos -, as reações variavam. A senhoria (a quem Marcelo oferece uma garrafa de vinho do Porto por ocasião da vitória em tribunal) faz a gentileza de lhe montar um escritório - na verdade, mais um recanto de trabalho - numa parte da varanda da sua casa. Não obstante, exige-lhe o pagamento de uma renda suplementar por ele. O excerto em questão não deixa de encerrar, segundo cremos, algum interesse, por descrever o espaço de trabalho de um jovem causídico considerado prometedor:

Apreciando o meu progresso, D. Antonieta quis arranjar-me um escritório em forma. Mandou pôr na varanda um biombo com uma porta, e num dos compartimentos assim formados, uma mesa, uma cadeira atrás da mesa e três cadeiras encostadas à grade da varanda. A outra parte da varanda foi transformada numa saleta de espera para os clientes, com duas cadeiras de balouço, meia dúzia de cadeiras simples e uma mesinha no meio.

Agradeci à minha hospedeira essa grande gentileza, e como tudo aquilo não eram móveis comprados para esse fim, mas móveis que havia em casa, supus 
que o arranjo não implicava pagamento de qualquer taxa, mas enganei-me, pois uma semana depois, aquela senhora, expondo-me as suas condições financeiras, que classificou de precárias, fixou-me uma taxa mensal, que eu achei modesta e prontamente me dispus a pagar (RODRIGUES, 1968, p. 214-215).

A criada Raquel e a futura apaixonada de Pelágio dão-lhe, a seu ver, menos atenção do que era merecedor. No entanto, cedo chega a uma conclusão que lhe é lisonjeira: era advogado, e tudo se justificava. Também neste passo o narrador em primeira pessoa não revela a menor intenção irônica em relação à situação que tão cuidadosamente descreve, como se não houvesse ali qualquer soberba de sua parte:

Naquele momento, qualquer coisa como ciúme roçou o meu coração. "Falam só dele (Pelágio) e não de mim? Não lhes interessa a minha pessoa nem um pouco? Mas teriam conversado a respeito de mim nos meus primeiros dias aqui?" Tais foram as perguntas que fiz então a mim mesmo, chegando a concluir que a beleza do rapaz era a causa daquele colóquio. Ponderando minutos depois, no que sucedera, lembrei-me de que o povo considerava o advogado um grande homem. Ele tem um certo respeito ao letrad (é assim que o povo lhe chama em concani), e esta circunstância talvez me estivesse distanciando dos sentimentos afectivos das duas moças (RODRIGUES, 1968, p. 218-219).

Mas cedo encontra a rapariga por quem se apaixona, Maria da Graça, com quem, logo na primeira conversa que travam - resultado de um encontro casual na praia - fala dos seus sucessos profissionais (e fica sabendo que a jovem, para além de formosa, de casta alta e instruída, é filha de um seu colega):

A certa altura ela deseja saber o meu nome, e quando eu lho digo, surpreendida, alvoraçada, exclama:

- Ah! O senhor é aquele advogado que fez uma brilhante defesa do réu num julgamento há poucos dias realizado?

- Sim, senhorinha.

- Meu pai contou um dia a minha mãe que ficara surpreendido com a sua oratória, com os seus brilhantes argumentos.

E, acto contínuo, ela levantou-se, apertou-me a mão, pronunciando as palavras "parabéns, doutor" e sentou-se. 
Perguntei, logo, como se chamava seu pai e ela respondeu-me:

- Rolando Serrão.

Oh! O pai da senhorinha é advogado, é meu amigo. Tenho então o prazer de conversar com filha do meu colega que, nesse dia, após o julgamento, ergueu o brinde da minha pessoa no bar onde ofereci cerveja a alguns colegas pelo meu sucesso! (RODRIGUES, 1968, p. 224)

\section{Conclusões}

A ironia presente em ambos os contos ao retratar o mundo jurídico se distingue, sobretudo, pela diferença de posição dos narradores. Enquanto o narrador de Silva Coelho é onisciente e faz observações ácidas sobre esse universo de forma crítica e distanciada, o narrador de Menezes Rodrigues é quem conta sua própria história de modo sério e crédulo, permitindo que o leitor menos ingênuo constate o quanto há ali de soberba, falsidade e hipocrisia. A ironia se constrói entre a ingenuidade do narrador e a perspicácia do leitor. A julgar por esses dois contos, o imaginário acerca do meio jurídico em Goa não era dos melhores, corroborando e ilustrando a deficiente formação com que podiam contar os provisionários.

Vimos já que o Law and Literature Movement tem desenvolvido esforços no sentido de apresentar uma lista de grandes referências literárias no âmbito do estudo do direito na literatura. Constatamos, também, que a esse núcleo inicial se podem aduzir muitos outros títulos, desde logo tendo em atenção o tema em análise. No entanto, e como refere Germano Schwartz: "em língua portuguesa, carece a definição de obras para tal propósito. Esse é um caminho em aberto" (Schwartz, 2006, p. 54), não obstante o contributo já prestado por alguns autores (entre os quais se encontra o atrás mencionado Moraes Godoy). Acrescentamos, neste ponto, uma sugestão: que nesse elenco não se esqueçam as muitas especificidades dos diferentes espaços onde o direito português foi intensivamente aplicado ao longo dos séculos, e nos quais se produziram suficientes trabalhos literários sobre temas jurídicos ou para-jurídicos. Elas são fundamentais para uma melhor compreensão das vivências jurídicas no chamado espaço lusófono, no qual o direito ainda serve de forte lastro. Goa acha-se, certamente, nessas condições. Dispondo de um 
acervo relativamente rico de textos relacionados com tais temas, estes acabam por constituir um importante contributo para quem se dedicar à articulação dos mecanismos jurídicos e sociais naquelas paragens em épocas passadas. Assim sendo, a vertente do direito na literatura pode constituir um auxílio de singular importância para todos os que se predisponham a estudar aquela que foi a cabeça do desaparecido Estado da Índia portuguesa.

\section{Referências bibliográficas}

CARREIRA, Ernestina. Índia. In: ALEXANDRE, Valentim e DIAS, Jill (Coord.). O Império Africano (1825-1890). Lisboa: Estampa, 1998. (Coleção Nova História da Expansão Portuguesa. Direção de Joel Serrão e A. H. de Oliveira Marques).

CHUEIRI, Vera Karam de. Shakespeare e o Direito. Revista da Faculdade de Direito, Universidade do Paraná, Curitiba, 2004.

CHUEIRI, Vera Karam de. Direito e Literatura. In: BARRETO, Vicente de Paulo (Dir.). Dicionário de filosofia do direito. Rio de Janeiro, São Leopoldo: Renovar, Unisinos, 2006.

COELHO, José da Silva. O que é ter a ciência das Manas. In: DEVI, Vimala e SEABRA, Manuel de (Org. e Coord.). A literatura indo-portuguesa. Vol. II. Lisboa: Junta de Investigações do Ultramar, 1971. (Antologia).

CUNHA, António Maria. A evolução do jornalismo na Índia portuguesa. Nova Goa: Typographia da "Casa Luso-Francesa", 1923.

CUNHA, João. Uma leitura crítica de Jacó e Dulce - cenas da vida indiana à luz do realismo de Eça de Queirós. Dissertação (Mestrado). Universidade de São Paulo, São Paulo, 2010.

CUNHA, Paulo Ferreira da. Direito e Literatura. Introdução a um Diálogo. Disponível em: <http:/ /www.hottopos.com/notand14/pfc.pdf>. Acesso em 30 jan 2011.

DERRIDA, Jacques. Acts of literature. London, New York: Routledge, 1992.

DEVI, Vimala e SEABRA, Manuel de. A literatura indo-portuguesa. Lisboa: Junta de Investigações do Ultramar, 1971, 2 vol.

FREITAS, Raquel Barradas de. Direito, linguagem e literatura: reflexões sobre o sentido e alcance das inter-relações. Breve estudo sobre dimensões de criatividade em Direito. Lisboa. Publicado como working paper em 06 fev. 2011, Faculdade de Direito da Universidade Nova de Lisboa. Disponível em: < http://www.estig.ipbeja. pt/ ac_direito/DireitoLinguagemLiteratura.pdf $>$. Acesso em 10 fev 2011.

GARMES, Hélder (Org.). Oriente, engenho e arte: imprensa e literatura de língua portuguesa em Goa, Macau e Timor Leste. São Paulo: Alameda, 2004. 
GODOY, Arnaldo Sampaio de Moraes. Direito e Literatura. Revista CEJ, Brasília, n. 22, jul/set 2003. Disponível em: <http://www2.cjf.jus.br/ojs2/index.php/cej/article/ viewFile/573/753>. Acesso em 03 fev 2011.

GODOY, Arnaldo Sampaio de Moraes. Direito e literatura. Os pais fundadores: John Henry Wigmore, Benjamin Nathan Cardozo e Lon Fuller. Disponível em: < http:/ / jus2.uol.com.br/doutrina/texto,asp?.id.=9995>. Acesso em 11 fev 2011.

HESPANHA, António Manuel. O caleidoscópio do direito: o direito e a justiça nos dias e no mundo de hoje. $2^{\text {a }}$. ed. Coimbra: Almedina, 2009.

KERBAUY, Ana Cristina. Ilustração Goana e Minerva Brasiliense: a sedimentação do romantismo em Goa e no Brasil. Dissertação (Mestrado). Universidade de São Paulo, São Paulo, 2008.

LOPES, António dos Mártires. Imprensa de Goa. Lisboa: Comissariado do Governo para os Assuntos do Estado da Índia, 1971.

LOPES, Maria de Jesus dos Mártires e MATOS, Paulo Lopes. Naturais, reinóis e lusodescendentes: a socialização conseguida. In: LOPES, Maria de Jesus dos Mártires (Coord.). O Império Oriental (1660-1820). Tomo II. Lisboa: Estampa, 2006. (Coleção Nova História da Expansão Portuguesa. Direção de Joel Serrão e A. H. de Oliveira Marques).

LOPES, Maria de Jesus dos Mártires e MATOS, Paulo Lopes. Goa setecentista: tradição e modernidade (1750-1800). Lisboa: Centro de Estudos dos Povos e Culturas de Expressão Portuguesa, Universidade Católica Portuguesa, 1999.

MACHADO, Everton V. Christianisme, castes et colonialisme dans le roman Les brahmanes (1866) du goannais Francisco Luis Gomes (1829-1869). Tese de Doutorado. Sorbonne, Université Paris IV, Paris, 2008.

MARI, Enrique. Derechoy Literatura. Algo de lo que sí sepuede hablar, pero en voz baja. Disponível em: <www.cervantesvirtual.com/servlet/SirveObras/23582844322570740087891/ cuaderno21/volII/DOXA21Vo.II_20.pdf>. Acesso em: 23/12/1998.

MINDA, Gary. Law and Literature at century's end. In: Cardozo Studies in Law and Literature, v. 9, n. 2, out/inverno de 1997, Cardozo School of Law.

OLIVEIRA, Luís Pedroso de Lima Cabral de e COSTA, Pedro do Carmo. Na dobragem do meio milénio. Elites e genealogias na Oriental Lisboa. Revista Raízes e Memórias, Associação Portuguesa de Genealogia, Lisboa, n. 26, 2010.

OLIVEIRA, Luís Pedroso de Lima Cabral de. Direito, sociedade e política: Manuel Duarte Leitão em Goa (1817-1821). e-Legal History Review, Universidad Complutense, Madrid, n. 7, jan. de 2009.

RODRIGUES, Alberto de Meneses. Flor campestre. Bastorá: Edição do autor, 1968.

SCHWARTZ, Germano. A Constituição, a Literatura e o Direito. Porto Alegre: Livraria do Advogado Editora, 2006.

SILVA, Joana Aguiar e. A prática judiciária entre Direito e Literatura. Coimbra: Almedina, 2001. 
XAVIER, Francisco João. Breve noticia da Imprensa Nacional de Goa, seguida de um catálogo das obras e escriptos publicados pela mesma imprensa desde a sua fundação. Nova Goa: Imprensa Nacional, 1876.

Recebido em 09 de fevereiro e aprovado em 10 de março de 2011. 